\title{
Prevalence of microalbuminuria in children with Type 1 (insulin-dependent) diabetes mellitus
}

\author{
E. R. Mathiesen, N.Saurbrey, E. Hommel and H.-H.Parving \\ Hvidöre Hospital, Klampenborg, Department of Paediatrics, Glostrup University Hospital, Glostrup, Denmark
}

\begin{abstract}
Summary. The prevalence of microalbuminuria was determined in children aged 7 to 18 years with Type 1 (insulin-dependent) diabetes of more than 2 years' duration. All patients $(n=102)$ attending 2 diabetes clinics were asked to collect 2 overnight timed urine samples for albumin analysis by radioimmunoassay. Complete urine collection was obtained in 97 patients (95\%). Overnight urinary albumin excretion rates were also measured in 36 healthy children matched for age and sex. Nineteen of the 97 patients $(20 \%)$ had microalbuminuria, i. e. overnight urinary albumin excretion rates above the upper normal level $(14 \mu \mathrm{g} / \mathrm{min})$ in both urine collections. Microalbuminuria was only demonstrated in patients aged $\geq 15$ years, prevalence $37 \%$ (19/52 patients). Arterial blood pressure was elevated, mean $122 / 84 \pm 11 / 9 \mathrm{mmHg}$, in
\end{abstract}

the microalbuminuric group (19 patients) compared to the age-matched normoalbuminuric diabetic group (33 patients), mean $117 / 74 \pm 10 / 10 \mathrm{~mm} \mathrm{Hg}, p<0.001$. The prevalence of simplex retinopathy was identical in these two groups, i.e. $25 \%$. Glycosylated haemoglobin was slightly higher in the microalbuminuric patients, $p<0.10$. Our cross-sectional study reveals a high prevalence $(37 \%)$ of persistent microalbuminuria, a stage highly predictive of later development of diabetic nephropathy, in Type 1 diabetic children aged $\geq 15$ years.

Key words: Arterial blood pressure, children, glycosylated haemoglobin, retinopathy, Type 1 diabetes, urinary albumin excretion.
Diabetic nephropathy is the main cause of increased morbidity and mortality in Type 1 (insulin-dependent) diabetic patients [1, 2]. Recently, several longitudinal studies have demonstrated that raised urinary albumin excretion (UAE) below the level of clinical albuminuria (Albustix), so-called microalbuminuria, strongly predicts the development of diabetic nephropathy in Type 1 diabetic patients [3-6]. Furthermore, cross-sectional studies have demonstrated increased arterial blood pressure and glycosylated haemoglobin in adult Type 1 diabetic patients with microalbuminuria $[5,7]$. Elevated $\mathrm{HbA}_{1 \mathrm{c}}$ has also been demonstrated in microalbuminuric children with Type 1 diabetes $[8,9]$, while blood pressure has been reported normal [8].

The aim of our cross-sectional study was (1) to determine the prevalence of microalbuminuria in children aged 7 to 18 years with Type 1 diabetes of more than 2 years' duration attending two diabetes clinics in $\mathrm{Co}-$ penhagen, and (2) to evaluate the relationship between $\mathrm{UAE}$ and arterial blood pressure, $\mathrm{HbA}_{1 \mathrm{c}}$ and frequency of retinopathy. The study began in 1985 as part of a prospective study on the evolution of diabetic nephropathy.

\section{Patients and methods}

\section{Patients}

All children (52 girls and 50 boys) between 7 and 18 years of age (median 15 years), with Type 1 diabetes of more than 2 years' duration, attending two diabetes clinics in the county of Copenhagen were asked to participate in the study (Table 1). All patients were insulin-dependent from the time of diagnosis, and all received at least 2 daily injections of insulin (mean dose $0.90 \mathrm{U} \cdot \mathrm{kg}^{-1} \cdot \mathrm{day}^{-1}$ ). None of the patients were taking any other drugs, and none had a history of renal or urinary tract disease. The non-diabetic control group consisted of 36 healthy children ( 14 boys, 22 girls) aged 8 to 18 years, median age 14 years.

All subjects gave their informed consent, and the experimental design was approved by the local Ethical Committee.

\section{Methods}

All subjects passed urine immediately before going to bed, discarded this sample, and recorded the time. The urine passed shortly after they got up in the morning was then collected without preservative, and this time was also noted. Any urine passed during the night was also collected into the same container. All children performed 2 overnight timed urine collections within 1 week. The urine volume was recorded and aliquots stored at $-20^{\circ} \mathrm{C}$ until analysis of albumin concentration 
Table 1. Clinical data of diabetic children with elevated urinary albumin excretion (UAE) (group A) compared to diabetic children with normal UAE (group B) and an age-matched subgroup of diabetic children with normal UAE (group C)

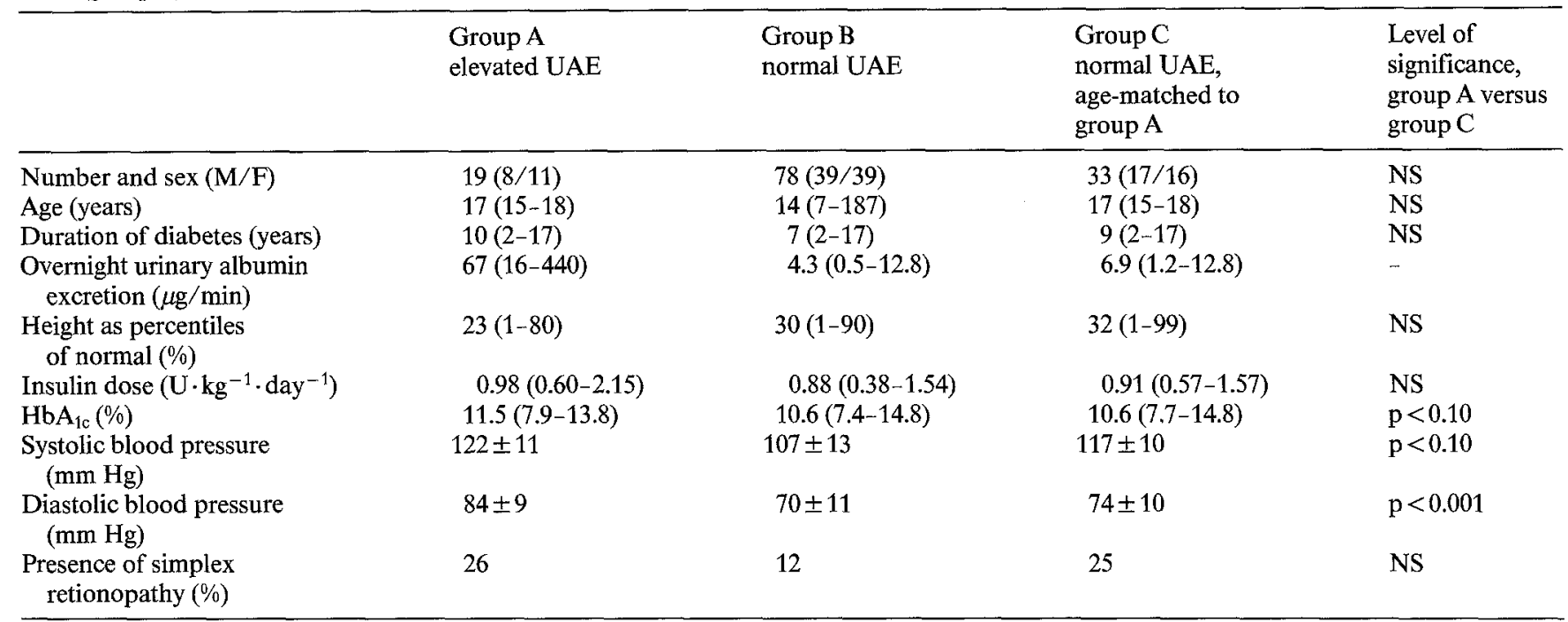

by radioimmunoassay with a single antibody [10]. This assay has a sensitivity of $0.5 \mathrm{mg} / 1$ and an interassay coefficient of variation of $9 \%$. The coefficient of variation for overnight urinary albumin excretion rate (UAE) collected at home was $48 \%$ in the diabetic children and $45 \%$ in healthy children. Complete urine collection was obtained in 97 diabetic children (95\%).

Arterial blood pressure was measured once in the sitting position after $10 \mathrm{~min}$ rest with a standard clinical mercury sphygmomanometer, cuff size $9 \mathrm{~cm}$ in patients below 12 years of age, and $12 \mathrm{~cm}$ in patients above 12 years of age. The measurements were performed "blindly", without any knowledge of the urinary albumin excretion rate. Diastolic blood pressure was recorded at the disappearance of the Korotkoff sounds (phase 5). Haemoblobin $\mathrm{A}_{1 \mathrm{c}}$ was measured with an isoelectric focusing method, normal range 4.1 to $6.1 \%$ [11]. The height of the diabetic child was expressed in percentiles of height of the age-related normal Danish population [12]. Retinopathy was assessed by direct ophthalmoscopy after pupillary dilation.

\section{Statistical analysis}

Since urinary albumin excretion rates and percentiles of height are not normally distributed, medians and ranges were used. Statistical analysis was performed with the Mann-Whitney non-parametric test for unpaired values. For the remaining variables, means and standard deviations (SD) and the unpaired Student's t-test (two-tailed) were used. The coefficient of variation for urinary albumin excretion was calculated as the square root of the mean variance of $\log _{e}$ transformed data ( 2 collections).

\section{Results}

The highest normal value recorded for overnight UAE was $14 \mu \mathrm{g} / \mathrm{min}$ (Fig. 1). Upper normal level was thus set to $14 \mu \mathrm{g} / \mathrm{min}$. Urinary albumin excretion rate was not related to the age of the subject, and no difference was demonstrated between girls and boys.

Nineteen out of 97 patients (20\%) had overnight UAE above the upper normal level in both urine collections (Fig. 2). Seven patients had 1 normal and 1 slightly elevated UAE. Therefore, these patients were asked to perform 2 additional overnight urine collections, which

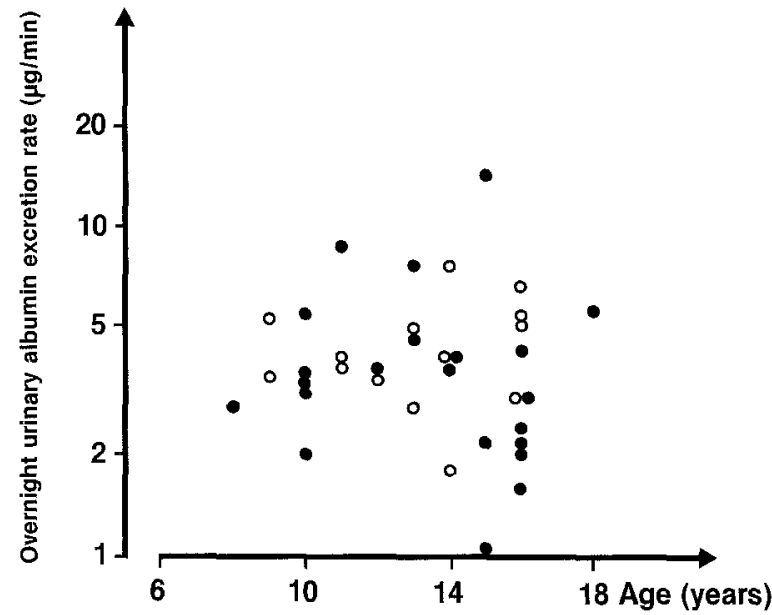

Fig. 1. Overnight urinary albumin excretion rate in normal children. - Female, $O$ male

revealed normal UAE rates in all cases. Elevated UAE was only demonstrated in children $\geq 15$ years of age (19 out of 52 patients, prevalence $37 \%$, Table 1 ). Two boys aged 16 and 17 years with a diabetes duration of 14 and 13 years had mean UAE of 440 and $321 \mu \mathrm{g} / \mathrm{min}$ respectively. These are above the upper level for the microalbuminuria ( $\geq 200 \mu \mathrm{g} / \mathrm{min}$ ), thus representing overt proteinuria. Overnight UAE increased with increasing duration of diabetes (Fig. 3).

Diastolic and mean arterial blood pressure values were significantly elevated $(p<0.001)$ in children with raised UAE compared to an age-matched subgroup of normoalbuminuric diabetic children (Table 1, Fig.4). There were no significant differences in age, duration of diabetes, insulin dose or presence of simplex retinopathy between these two groups (Table 1 ). $\mathrm{HbA}_{1 \mathrm{c}}$ was higher $(p<0.10)$, and body height tended to be lower, in children with raised UAE compared to age-matched normoalbuminuric diabetic children (Table 1). 


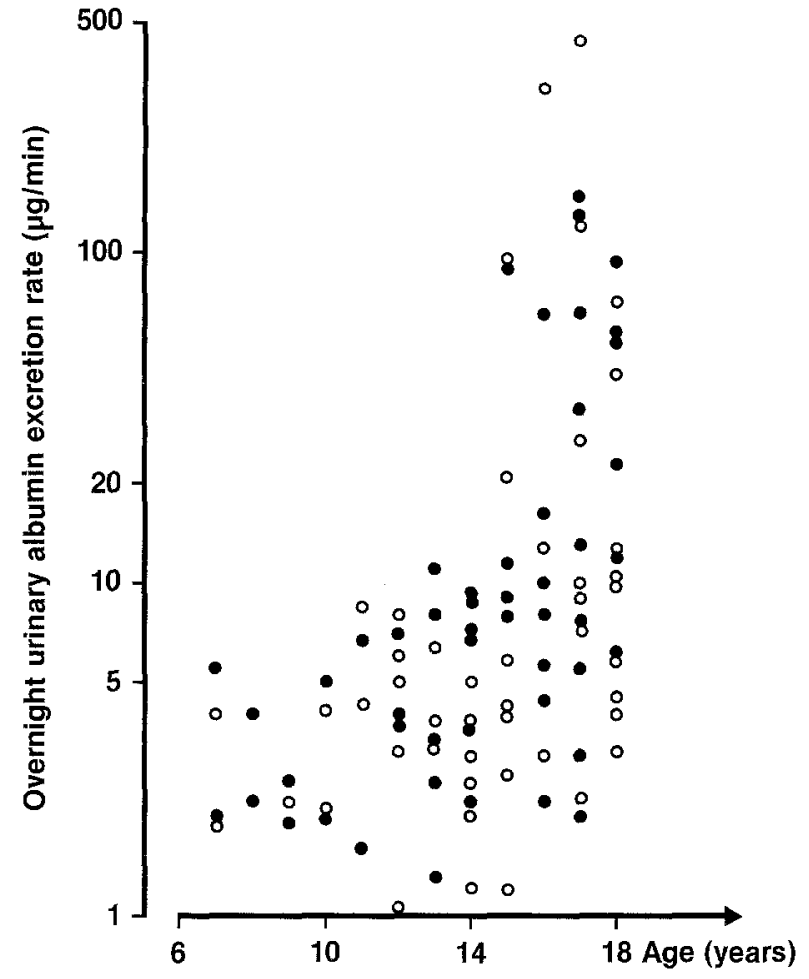

Fig. 2. Overnight urinary albumin excretion rate in diabetic children. - female, $O$ male

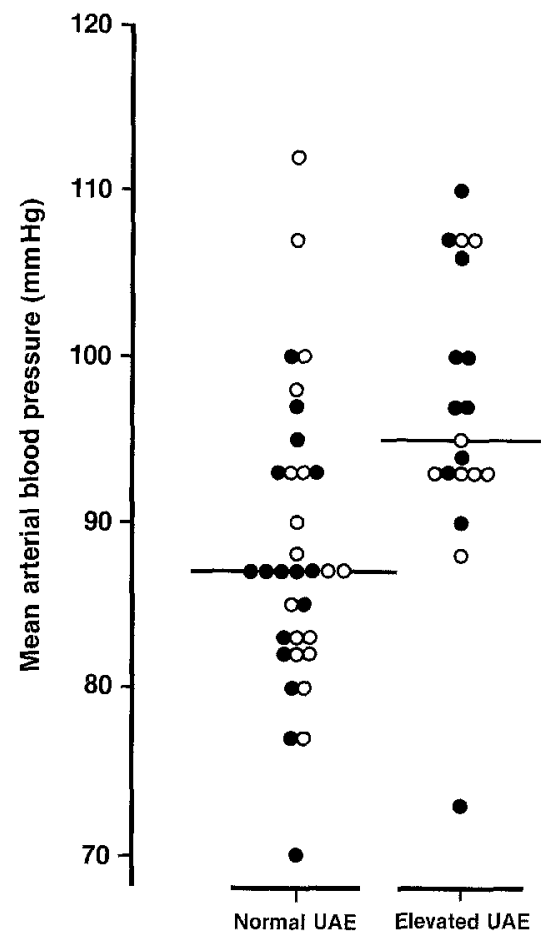

Fig.4. Individual mean arterial blood pressure in age-matched diabetic children with normal and elevated overnight urinary albumin excretion (UAE). (Median value 88 and $95 \mathrm{~mm} \mathrm{Hg}, p<0.001$ ). $\mathrm{fe}-$ male, $O$ male

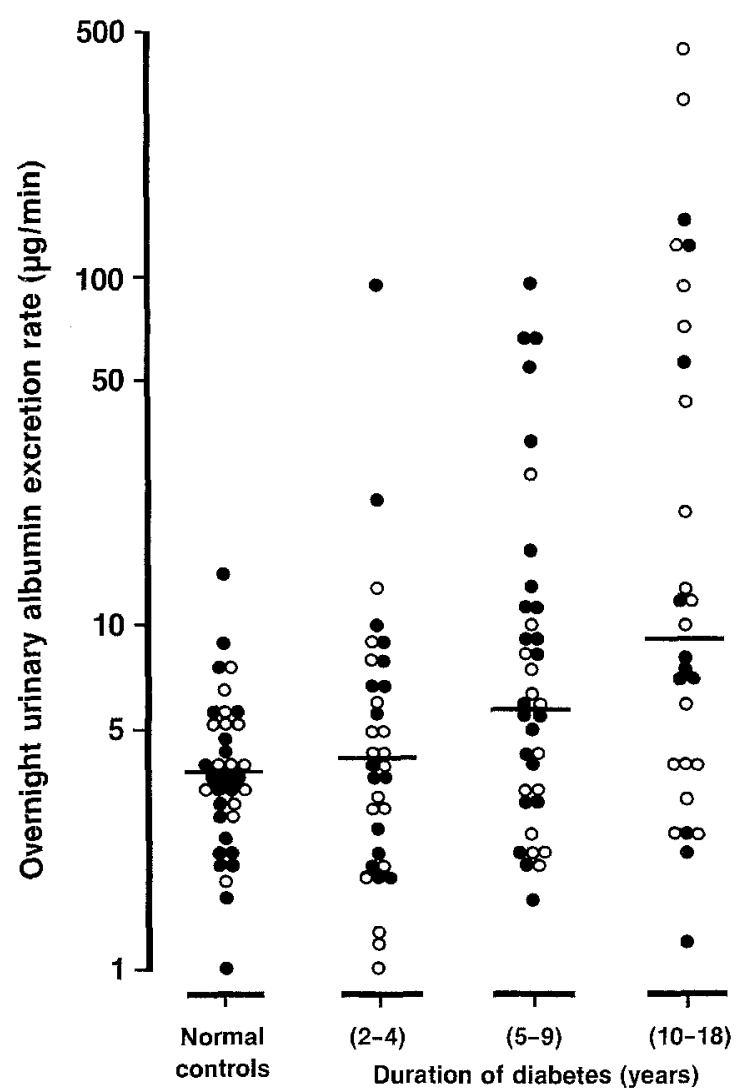

Fig.3. Overnight urinary albumin excretion rate in relation to duration of diabetes. ( - median value). female, $O$ male

\section{Discussion}

Our cross-sectional study has revealed a high prevalence $(20 \%)$ of persistent microalbuminuria in children with Type 1 diabetes. Elevated overnight UAE was demonstrated only in children $\geq 15$ years of age. We have confirmed and extended the observations of $\mathrm{Da}-$ vies et al. [8], which were based on one 24-h urine collection in hospital (prevalence of microalbuminuria, 15.7\%). Rowe et al. [9] found that $15 \%$ of a selected group of diabetic children had microalbuminuria based on a single overnight UAE. Ellis et al. [13] found a much higher prevalence of microalbuminuria $(33 \%)$ in a group of diabetic children partly selected for the presence of retinopathy.

The timed overnight urine collection was chosen to avoid the effects of posture and exercise on albuminuria whilst still allowing a reasonable time interval for collection. This screening procedure for microalbuminuria was accepted by $95 \%$ of the diabetic patients. Elevated overnight UAE rates strongly predict the later development of diabetic nephropathy [4]. The risk of developing nephropathy is highest (44\%) in Type 1 diabetic patients with diabetes onset in childhood [2]. The present and previous studies [8,9] suggest that screening for microalbuminuria can be restricted to children above the age of 12 years. The present and previous findings of a high day-to-day variation in UAE strongly suggest 
that repeated measurements should be performed in order to diagnose incipient and overt diabetic nephropathy $[14,15]$. This day-to-day variation in UAE cannot be reduced significantly by the calculation of an albumin/ creatinine ratio $[14,15]$. Thus, the huge variation in UAE reflects a biological phenomenon and not incomplete urine collections.

Previous studies $[8,9]$, as well as the present study, suggest that microalbuminuria in Type 1 diabetic children is positively related to age, diabetes duration and poor glycaemic control. Elevated $\mathrm{HbA}_{1 c}$ has also been demonstrated in microalbuminuric adults with Type 1 diabetes [7]. Eight months of near normal blood glucose control achieved by the use of continuous subcutaneous insulin infusion diminished the UAE during everyday life in adult Type 1 diabetic patients with microalbuminuria [16]. Thus, long-term strict metabolic control may delay or even prevent the progression from microalbuminuria to macroalbuminuria, i.e. diabetic nephropathy. This crucial question is currently being investigated [17]. The progression in microalbuminuria is significantly reduced after 24 months of continuous subcutaneous insulin infusion compared to conventional insulin treatment [18].

A major novel finding in our study was the demonstration of elevated diastolic and mean arterial blood pressure values in children with increased UAE rates. Davies et al. [8] demonstrated increased diastolic blood pressure measurements in diabetic children compared to non-diabetic children. Elevated arterial blood pressure is present in adult Type 1 diabetic patients with microalbuminuria [5, 7]. Recently we have demonstrated a considerable decrease in urinary albumin excretion (44\%) during acute blood pressure reduction in normotensive Type 1 diabetic patients with persistent microalbuminuria [19]. Elevated blood pressure accelerates, and effective blood pressure reduction slows down, the progression of diabetic nephropathy and reduces albuminuria [20]. Thus, the treatment of blood pressure elevations at much lower levels than attempted in the past may have a beneficial effect on the progression from microalbuminuria to macroalbuminuria, i.e. diabetic nephropathy.

Acknowledgements. We are very grateful for the assistance from K. Dyrlev (nurse), L.Skovsbo technician and S. Vestermark (chief physician).

\section{References}

1. Andersen AR, Christiansen JS, Andersen JK, Kreiner S, Deckert T (1983) Diabetic nephropathy in Type 1 (insulin-dependent) diabetes: an epidemiological study. Diabetologia 25: 496-501

2. Borch-Johnsen K, Andersen PK, Deckert T (1985) The effect of proteinuria on relative mortality in Type 1 (insulin-dependent) diabetes mellitus. Diabetologia 28: 590-596

3. Parving H-H, Oxenbøll B, Svendsen PAa, Christiansen JS, Andersen AR (1982) Early detection of patients at risk of developing diabetic nephropathy: a longitudinal study of urinary albumin excretion. Acta Endocrinol (Copenh) 100: 550-55

4. Viberti GC, Hill RD, Jarrett RJ, Argyropaulos A, Mahmud Y, Keen H (1982) Microalbuminuria as a predictor of clinical nephropathy in insulin-dependent diabetes mellitus. Lancet 1: $1430-32$

5. Mathiesen ER, Oxenbøll B, Johansen K, Svendsen PAa, Deckert T (1984) Incipient nephropathy in Type 1 (insulin-dependent) diabetes. Diabetologia 26: 406-10

6. Mogensen CE, Christensen CK (1984) Predicting diabetic nephropathy in insulin-dependent patients. New Engl J Med 311: $89-93$

7. Wisemann M, Viberti G, Mackintosh D, Jarett RJ, Keen H (1984) Glycaemia, arterial blood pressure and microalbuminuria in Type 1 (insulin-dependent) diabetes mellitus. Diabetologia 26:401-406

8. Davies AG, Price DA, Postlethwaite RJ, Addison GM, Burn JL, Fielding BA (1985) Renal function in diabetes mellitus. Arch of Disease in Childhood 60: 299-304

9. Rowe DJF, Hayward M, Bagga H, Betts P (1984) Effect of glycaemic control and duration of disease on overnight albumin excretion in diabetic children. Br Med J 289:957-959

10. Christensen C, Ørskov C (1984) Rapid screening PEG radioimmunoassay for quantification of pathological microalbuminuria. Diabetic Nephropathy 3: 92-94

11. Mortensen HB (1980) Quantitative determination of hemoglobin $A_{1 c}$ by thinlayer isoelectric focusing. $J$ Chromatography 182 : 325-333

12. Andersen E, Hutchings B, Jansen J, Nyholm M (1982) Højde og vækst hos danske børn. Ugeskrift for læger 144: 1760-1765

13. Ellis D, Becker DJ, Danemann D, Lobes L, Drash AL (1983) Proteinuria in children with insulindependent diabetes: Relationship to duration of disease, metabolic control, and retinal changes. J Pediatr 102: 673-680

14. Feldt-Rasmussen B, Mathiesen ER (1985) Variability of urinary albumin excretion in incipient diabetic nephropathy. Diabetic Nephropathy 3: 101-104

15. Price DA, Fielding BA, Davies AG, Postlethwaite RJ (1985) Shortterm variability of urinary albumin excretion in normal and diabetic children. Diabetic Nephropathy 4: 169-172

16. The Kroc Collaborative Study Group (1984) Blood glucose control and the evolution of diabetic retinopathy and albuminuria. $\mathrm{N}$ Engl J Med 311: 365-372

17. Feldt-Rasmussen B, Mathiesen ER, Hegedüs L, Deckert T (1986) Kidney function during 12 months of strict metabolic control in insulindependent diabetic patients with incipient nephropathy. $\mathrm{N}$ Engl J Med 314: 665-670

18. Feldt-Rasmussen B, Mathiesen ER, Deckert T (1986) Effect on the progression of diabetic renal disease during 2 years of strict metabolic control in insulin-dependent diabetes. Diabetes 35 (Suppl 1): $107 \mathrm{~A}$

19. Hommel E, Mathiesen ER, Edsberg B, Bahnsen M, Parving H-H (1986) Acute reduction of arterial blood pressure reduces urinary albumin excretion in Type 1 (insulin-dependent) diabetic patients with incipient nephropathy. Diabetologia $29: 211-215$

20. Parving H-H, Andersen AR, Smidt UM, Svendsen PAa (1983) Early aggressive antihypertensive treatment reduces rate of decline in kidney function in diabetic nephropathy. Lancet 1: 1175-79

Received: 19 February 1986

and in revised form: 14 July 1986

Dr. Elisabeth R. Mathiesen

Hvidøre Hospital

Emiliekildevej 1

DK-2930 Klampenborg

Denmark 